International Journal of Pure and Applied Mathematics

Volume 114 No. 3 2017, 537-551

ISSN: 1311-8080 (printed version); ISSN: 1314-3395 (on-line version)

url: http://www.ijpam.eu

doi: 10.12732/ijpam.v114i3.10

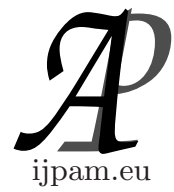

\title{
THE APPLICATION OF POTENTIAL METHOD IN \\ DECISION MAKING FOR MULTI-ATTRIBUTE OF CATERING SERVICE COMPANIES
}

\author{
Siti Salwana Mamat ${ }^{1} \S$, Tahir Ahmad ${ }^{2}$, Siti Rahmah Awang ${ }^{3}$ \\ ${ }^{1,2}$ Department of Mathematical Science \\ Faculty of Science \\ Universiti Teknologi Malaysia \\ 81310, Skudai, Johor, MALAYSIA \\ ${ }^{2}$ Centre for Sustainable Nanomaterials \\ Ibnu Sina Institute for Scientific and Industrial Research \\ Universiti Teknologi Malaysia \\ 81310, UTM, Skudai, Johor, MALAYSIA \\ ${ }^{3}$ Faculty of Management \\ Universiti Teknologi Malaysia \\ 81310, UTM, Skudai, Johor, MALAYSIA
}

\begin{abstract}
Analytic Hierarchy Process is a method used in structuring, measuring and synthesizing criteria, in particular ranking of multiple criteria in decision making problems. On the other hand, Potential Method is a ranking procedure that utilizes preference graph. Two nodes are adjacent if they are compared in a pairwise comparison whereby the assigned arc is oriented towards the more preferred node. In this paper, Potential Method is used to solve problems in catering service selection. The Potential Method is found to be comparable to Modified Fuzzy Logarithmic Least Square Method in weight determination.
\end{abstract}

AMS Subject Classification: $90 \mathrm{~B} 50$

Key Words: decision processes, multiple criteria analysis, potential method

Received: December 28, 2016

Revised: $\quad$ April 16, 2017

Published: $\quad$ May 23, 2017

(c) 2017 Academic Publications, Ltd. url: www.acadpubl.eu

$\S_{\text {Correspondence author }}$ 


\section{Introduction}

The Analytic Hierarchy Process (AHP) proposed by Saaty [1] is widely used in Multi Criteria Decision Making (MCDM). It is a tool for weight estimation. Analytic Hierarchy Process has been used as decision tool in many sectors such as government [2], business [3], industry [4], healthcare [5], and education [6]. Analytic Hierarchy Process builds a hierarchy of decision items via comparison between each pair of items expressed in a matrix form. The comparison produces scores that measure the importance of each item. The determination of weight is important in AHP. Some of these approaches are Extent Analysis, Potential Method (PM), Least Square Method, Minimax Method and Absolute Deviation Method.

Extent Analysis is an approach used to determine fuzzy weights in AHP. According to Wang et al. [7], Extent Analysis was introduced to obtain crisp priority vector from a triangular fuzzy comparison matrix. Extent Analysis may assign a zero weight to some important decision criteria. However, in some cases, information from a fuzzy comparison matrix is not applicable for Extent Analysis, as it will lead to unsatisfactory results as reported in Aggarwal and Singh [8].

Fuzzy Logarithmic Least Square Method (FLLSM) was introduced to overcome the drawbacks of the Extent Analysis. The FLLSM was formulated as a constrained nonlinear optimization model. It can directly derive normalized triangular fuzzy weights for both complete and incomplete triangular fuzzy comparison matrix. The FLLSM can be used in solving complex MCDM problems. Wang et al. [9] suggested to use FLLSM to obtain triangular fuzzy weights from a triangular fuzzy comparison matrix in constrained nonlinear optimization model to produce fuzzy weight with narrow support intervals.

Potential Method was introduced by Čaklović [10]. The method has been further investigated and developed by Caklović and his co-researchers [11], [12] and [13]. It is a simple and flexible method since it is based on oriented graph approach. It is also a ranking procedure that requires a preference graph as an input. The nodes of the preference graph represent alternatives. Two nodes are adjacent if they are compared in pairwise and the arc is oriented towards the more preferred node.

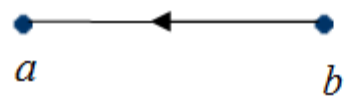

We can say that node $a$ is more preferred than node $b$, in notation $a \geq b$ 
such that $a$ is terminal (ingoing) node $a$ and $b$ is the initial (outgoing) node. We also say that $a$ leaves $b$ and $b$ enters $a$.

\section{Basic Definitions}

Definition 1. [14] A fuzzy number is a function $A: R \rightarrow[0,1]$ such that:

(a) $A$ is normal (there exists $x_{0} \in R$ with $\mu_{A}\left(x_{0}\right)=1$ ).

(b) $A_{\alpha}$ is closed interval for all $\alpha \in[0,1]$.

(c) $A_{\alpha}$ is convex for all $\alpha \in[0,1]$.

Definition 2. [15] A triangular fuzzy number is a special case of a fuzzy number. It is defined by a triplet $\tilde{A}=(l, m, u)$. This representation is interpreted as a membership function $\mu_{\tilde{A}}: R \rightarrow[0,1]$ such that

$$
\mu_{\tilde{A}}=\left\{\begin{array}{cc}
x-l / m-l, & l \leq x \leq m \\
u-x / u-m, & m \leq x \leq u \\
0, & \text { otherwise }
\end{array}\right.
$$

A fuzzy comparison matrix with triangular fuzzy number is expressed by

$$
\mu_{\tilde{\mathrm{A}}}=\left(\tilde{\mathrm{a}}_{\mathrm{ij}}\right)_{\mathrm{nxn}}=\left[\begin{array}{cccc}
(1,1,1) & \left(l_{12}, m_{12}, u_{12}\right) & \cdots & \left(l_{1 n}, m_{1 n}, u_{1 n}\right) \\
\left(l_{21}, m_{21}, u_{21}\right) & (1,1,1) & \cdots & \left(l_{2 n}, m_{2 n}, u_{2 n}\right) \\
\vdots & \vdots & \ddots & \vdots \\
\left(l_{n 1}, m_{n 1}, u_{n 1}\right) & \left(l_{n 2}, m_{n 2}, u_{n 2}\right) & \cdots & (1,1,1)
\end{array}\right],
$$

where $\tilde{a}=\left(l_{i j}, m_{i j}, u_{i j}\right)$ and $a_{i j}^{-1}=\left(\frac{1}{u_{j i}}, \frac{1}{m_{j i}}, \frac{1}{l_{j i}}\right)$ for $i, j=1, \ldots, n$ with $i \neq j$.

\subsection{Extent Analysis}

Chang [15] proposed five steps for Extent Analysis in order to derive the priority of a fuzzy comparison matrix. First, sum up each row of $\tilde{A}$ by fuzzy addition:

$$
R S_{i}=\sum_{j=1}^{n} \tilde{a}_{i j}=\left(\sum_{j=1}^{n} l_{i j}, \sum_{j=1}^{n} m_{i j}, \sum_{j=1}^{n} u_{i j}\right), \quad i=1, \ldots, n,
$$

where $R S_{i}$ defines the row sum.

Second, normalize the above row sums $R S_{i}, i=1, \ldots, n$ by

$$
\tilde{S}_{i}=\frac{R S_{i}}{\sum_{j=1}^{n} R S_{j}}
$$




$$
=\left(\frac{\sum_{j=1}^{n} l_{i j}}{\sum_{k=1}^{n} \sum_{j=1}^{n} u_{k j}}, \frac{\sum_{j=1}^{n} m_{i j}}{\sum_{k=1}^{n} \sum_{j=1}^{n} m_{k j}}, \frac{\sum_{j=1}^{n} u_{i j}}{\sum_{k=1}^{n} \sum_{j=1}^{n} l_{k j}}\right), \quad i=1, \ldots, n .
$$

Third, compute the degree of possibility for $\tilde{S}_{i} \geq \tilde{S}_{j}$ by

$$
V\left(\tilde{S}_{i} \geq \tilde{S}_{j}\right)=\left\{\begin{array}{ccc}
1 & \text { if, } & m_{i} \geq m_{j}, \\
\frac{u_{i}-l_{j}}{\left(u_{i}-m_{i}\right)+\left(m_{i}-l_{j}\right)}, & \text { if } & l_{j} \leq u_{i}, \\
0, & & i, j=1, \ldots, n ; j \neq i, j \\
\text { otherwise }
\end{array}\right.
$$

where $\tilde{S}_{i}=\left(l_{i}, m_{i}, u_{i}\right)$ and $\tilde{S}_{j}=\left(l_{j}, m_{j}, u_{j}\right)$.

Fourth, calculate the degree of possibility for $\tilde{S}_{i}$ over all the other $n-1$ fuzzy numbers by

$$
V\left(\tilde{S}_{i} \geq \tilde{S}_{j}: j=1, \ldots, n ; j \neq 1\right)=\min _{j=\{1, \ldots, n\}, j \neq 1} V\left(\tilde{S}_{i} \geq \tilde{S}_{j}\right), \quad i=1, \ldots, n .
$$

Finally, define the priority vector $W=\left(w_{1}, \ldots, w_{n}\right)^{T}$ of the fuzzy comparison matrix $\tilde{A}$ as

$$
w_{i}=\frac{V\left(\tilde{S}_{i} \geq \tilde{S}_{j}: j=1, \ldots, n ; j \neq 1\right)}{\sum_{k=1}^{n} V\left(\tilde{S}_{i} \geq \tilde{S}_{j}: j=1, \ldots, n ; j \neq k\right)}, \quad i=1, \ldots, n,
$$

where $w_{i}$ defines the weight

\subsection{Modified FLLSM}

Yuen and Lau [16] pointed out that Modified FLLSM derives priorities from fuzzy triangular matrix, $\tilde{A}$.

First, calculate local weights as the following form:

$$
\begin{aligned}
\operatorname{Min} J & =\sum_{i=1}^{n} \sum_{j=1, j \neq i}^{n}\left(\left(\ln w_{i}^{L}-\ln w_{j}^{U}-\ln l_{i j}\right)^{2}+\left(\ln w_{i}^{M}-\ln w_{j}^{M}-\ln m_{i j}\right)^{2}\right. \\
& \left.+\left(\ln w_{i}^{U}-\ln w_{j}^{L}-\ln u_{i j}\right)^{2}\right),
\end{aligned}
$$

subject to

$$
\left\{\begin{array}{c}
m_{i}^{L}+\sum_{j=1, j \neq i}^{n} w_{j}^{U} \geq 1 \\
m_{i}^{U}+\sum_{j=1, j \neq i}^{n} w_{j}^{L} \leq 1 \\
\sum_{i=1}^{n} w_{i}^{M}=1 \\
\sum_{i=1}^{n} w_{i}^{L}+w_{i}^{U}=2 \\
w_{i}^{U} \geq w_{i}^{M} \geq w_{i}^{L}>0
\end{array} \quad i=1, \ldots, n .\right.
$$


The optimum solution to the above model forms normalized fuzzy weights $\tilde{w}_{i}=\left(w_{i}^{L}, w_{i}^{M}, w_{i}^{U}\right), i=1, \ldots, n$ to obtain the local fuzzy weights.

Second, calculate the global fuzzy weight by solving two linear programming models and an equation for each decision alternative.

$$
\begin{aligned}
& w_{A_{i}}^{L}=\min _{W \in \Omega_{w}} \sum_{j=1}^{m} w_{i j}^{L} w_{j}, i=1, \ldots, n . \\
& w_{A_{i}}^{U}=\max _{W \in \Omega_{w}} \sum_{j=1}^{m} w_{i}^{U} w_{j}, i=1, \ldots, n . \\
& w_{A_{i}}^{M}=\sum_{j=1}^{m} w_{i j}^{M} w_{j}^{M}, i=1, \ldots, n .
\end{aligned}
$$

where $\Omega_{w}=\left\{W=\left(w_{1}, \ldots, w_{m}\right) \mid w_{j}^{U} \geq w_{j}^{M} \geq w_{j}^{L}, \sum_{j=1}^{m} w_{j}=1, \ldots, m\right\}$ is a set of fuzzy weights.

\subsection{Potential Method}

Čaklović and Sego [11] used a preference graph to present their pairwise comparisons of a set of alternatives $V$. A pair $\alpha=(u, v) \in V \times V$ is declared to be an arc of a directed graph if $v$ is more preferred than $u$. The set of arcs is denoted by $A$. A function $F: A \rightarrow \mathbb{R}$ which assigns to each arc $\alpha \in A$ as its weight is called a preference flow. A preference flow is always a non-negative and can be represented by $m \times 1$ matrix. A directed graph $(V, A)$ is called a preference graph.

A preference graph is complete if each pair of alternatives is compared, i.e. if for each pair $\{i, j\}$ of vertices, then $(i, j) \in A$ or $(j, i) \in A$. For a given flow $F$ a preference graph $(V, A)$ with $\alpha \in A$ is written as $F(-\alpha)=-F(\alpha)$.

Let denote $n=$ Card $V$ and $m=$ Card $A$. An $m \times n$ incidence matrix of preference graph is denoted by $B$ such that

$$
B_{\alpha, i}=\left\{\begin{array}{ccccc}
-1, & \text { if } & \alpha & \text { leaves } & i \\
1, & \text { if } & \alpha & \text { enters } & i \\
0, & & & \text { otherwise }
\end{array}\right.
$$

An example of a preference graph in grading process was considered by Bouyssou et al. as discussed in Čaklović [10]. 


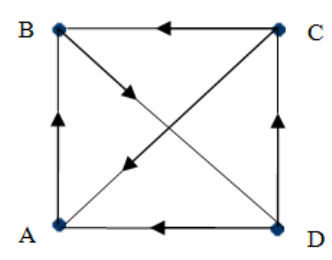

$$
B=\left[\begin{array}{cccc}
-1 & 1 & 0 & 0 \\
1 & 0 & -1 & 0 \\
1 & 0 & 0 & -1 \\
0 & 1 & -1 & 0 \\
0 & -1 & 0 & 1 \\
0 & 0 & 1 & -1
\end{array}\right]
$$

Figure 1: The preference graph and its incidence matrix.

In a hierarchical decision structure, each node except the last level is a parent node for its children from some other level. A parent node may be considered as the criterion for its children evaluation. The only restriction is that children of the parent should be in the same level. The conservation law restricts the sum of the weights of nodes in some level set, i.e. the sum of the weights of their parents.

Potential Method calculates the weights of nodes in some level in the following way. First, the weight of the goal is set to be 1 . The aggregation of flows is made over the set of all parents if it is not ranked. Potential $X$ is calculated after the weight $w$ is obtained using the formula

$$
w=k \cdot \frac{a^{X}}{\left\|a^{X}\right\|_{1}},
$$

where $\|.\|_{1}$ represents $l_{i}$-norm and $k$ is the sum of weights of the parents (usually $k=1$ ). Parameter $a$ is chosen to be 2 as suggested by Caklović [10]. The process is repeated until the bottom level of the hierarchy is ranked.

\section{Implementation}

In Wang et al. [7], a big Turkish textile company had to make a contract with one catering firm. Alternative catering firms were Durusu, Mertol and Afiyetle. In this study, the goal was to select the best catering firm among the alternatives. The criteria to be considered were hygiene $(\mathrm{H})$, quality of meal (QM) and quality of service (QS). In order to make the selection, 11 sub criteria needed to be considered. The three sub criteria of $\mathrm{H}$ were hygiene of meal (HM), hygiene of service personnel (HSP) and hygiene of service vehicles (HSV). The variety of meal (VM), complementary meals in a day (CoM), calorie of meal (CaM) and taste of meal (TM) were four sub criteria of QM. The 
four sub criteria of QS were behavior of service personnel (BSP), service time (ST), communication on phone (CP) and problem solving (PS) ability. The hierarchical structure of the problem is presented in Figure 2. A decisionmaking group consisting of the customers of the catering firms and five experts were responsible for making comparisons and constructing fuzzy comparison matrices.

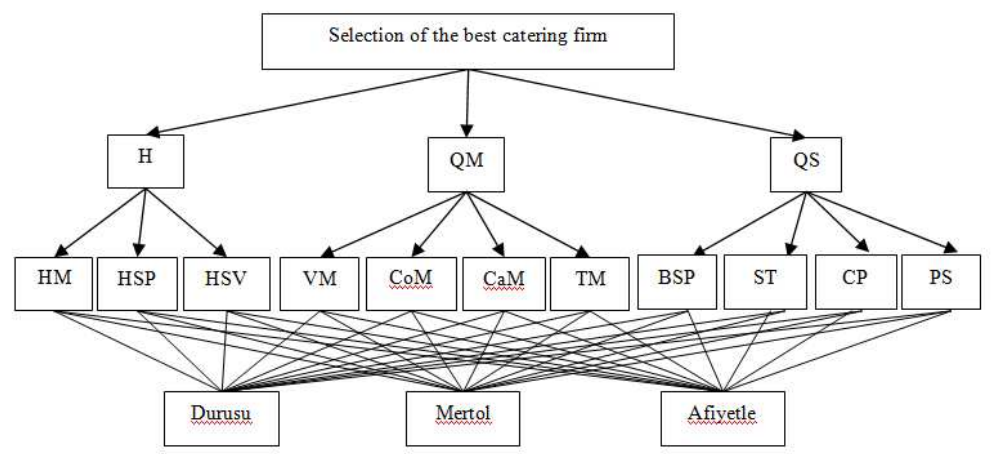

Figure 2: The hierarchy problem

The fuzzy comparison matrices in Table 1-15 are all taken from Wang et al. [7]. The fuzzy comparison matrix relevant to goal is given in Table 1. The PM is based on directed graph approach. Figure 3 illustrates the preference graph for the identified goal, whereby QS is more preferred than $\mathrm{H}$ and QM whereas $\mathrm{H}$ preferred over QM.

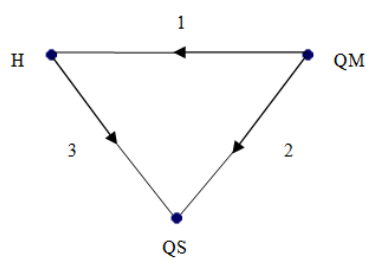

Figure 3: The preference graph-goal 
The incidence matrix $B$ and the potential $X$ of goal are

$$
\left(\begin{array}{ccc}
1 & -1 & 0 \\
-1 & 0 & 1 \\
0 & -1 & 1
\end{array}\right) \text { and }\left(\begin{array}{c}
-0.667 \\
-1 \\
1.667
\end{array}\right) \text { respectively. }
$$

The priority vector with respect to the goal, criteria and sub criteria are given in Table 1-15. The weights are determined via PM. The determined weights obtained from Wang et al. [7] by using Extent Analysis and Modified FLLSM are presented in these tables.

\begin{tabular}{ccccccc}
\hline Criteria & H & QM & QS & \multicolumn{3}{c}{ Priority Vector } \\
& & & & Extent & Modified & Potential \\
& & & & Analysis & F LLSM & Method \\
\hline H & $(1,1,1)$ & $(2 / 3,1,3 / 2)$ & $(2 / 7,1 / 3,2 / 5)$ & 0 & $(0.1781,0.2098,0.2477)$ & 0.146 \\
QM & $(2 / 3,1,3 / 2)$ & $(1,1,1)$ & $(2 / 5,1 / 2,2 / 3)$ & 0 & $(0.1933,0.2402,0.3015)$ & 0.116 \\
QS & $(5 / 2,3,7 / 2)$ & $(3 / 2,2,5 / 2)$ & $(1,1,1)$ & 1 & $(0.5302,0.5499,0.5990)$ & 0.738 \\
\hline
\end{tabular}

Table 1: Fuzzy comparison matrix of decision criteria with respect to goal and its priority vectors

\begin{tabular}{ccccccc}
\hline $\begin{array}{c}\text { Sub- } \\
\text { Criteria }\end{array}$ & HM & HSP & HSV & \multicolumn{3}{c}{ Priority Vector } \\
& & & & Extent & Modified & Potential \\
& & & & Analysis & F LLSM & Method \\
\hline HM & $(1,1,1)$ & $(2 / 3,2,5 / 2)$ & $(2 / 7,1 / 3,2 / 5)$ & 0.70 & $(0.4615,0.5000,0.5128)$ & 0.055 \\
HSP & $(2 / 5,1 / 2,3 / 2)$ & $(1,1,1)$ & $(2 / 5,1 / 2,2 / 3)$ & 0.15 & $(0.2051,0.2500,0.3077)$ & 0.044 \\
HSV & $(5 / 2,3,7 / 2)$ & $(2 / 3,1,3 / 2)$ & $(1,1,1)$ & 0.15 & $(0.2051,0.2500,0.3077)$ & 0.047 \\
\hline
\end{tabular}

Table 2: Fuzzy comparison matrix of sub-criteria with respect to hygiene and its priority vectors

Tables 16-18 show the local weights for criteria H, QM and QS for Extent Analysis, Modified FLLSM and the PM. The global weights for goal can be referred in Table 19.

Table 19 summarizes the weight for the three catering firms. The weight of Afiyetle obtained by Extent Analysis is 0.317, while Modified FLLSM and PM give 0.4072 and 0.437, respectively. The weights for Durusu are 0.3096 and 0.286 by using Modified FLLSM and PM. The weight for Durusu is 0.050 by using Extent Analysis and 0.634 for Mertol. This weight is slightly higher 


\begin{tabular}{|c|c|c|c|c|c|c|c|}
\hline Sub- & VM & $\mathrm{CoM}$ & $\mathrm{CaM}$ & $\mathrm{TM}$ & & $\begin{array}{l}\text { Priority } \\
\text { Vector }\end{array}$ & \\
\hline \multirow[t]{2}{*}{ Criteria } & & & & & Extent & Modified & Potential \\
\hline & & & & & Analysis & F LLSM & Method \\
\hline VM & $(1,1,1)$ & $(3 / 2,2,5 / 2)$ & $(2 / 7,1 / 3,2 / 5)$ & $(5 / 2,3,7 / 2)$ & 0.19 & $\begin{array}{l}(0.2188 \\
0.2488 \\
0.2783)\end{array}$ & 0.030 \\
\hline $\mathrm{CoM}$ & $(2 / 5,1 / 2,2 / 3)$ & $(1,1,1)$ & $(2 / 7,1 / 3,2 / 5)$ & $(7 / 2,4,9 / 2)$ & 0.05 & $\begin{array}{l}(0.1729 \\
0.1890 \\
0.2107)\end{array}$ & 0.028 \\
\hline $\mathrm{CaM}$ & $(5 / 2,3,7 / 2)$ & $(5 / 2,3,7 / 2)$ & $(1,1,1)$ & $(5 / 2,3,7 / 2)$ & 0.76 & $\begin{array}{l}(0.4371 \\
0.4768 \\
0.5095)\end{array}$ & 0.034 \\
\hline $\mathrm{TM}$ & $(2 / 7,1 / 3,2 / 5)$ & $(2 / 9,1 / 4,2 / 7)$ & $(2 / 7,1 / 3,2 / 5)$ & $(1,1,1)$ & 0 & $\begin{array}{l}(0.0815 \\
0.0854 \\
0.0911)\end{array}$ & 0.024 \\
\hline
\end{tabular}

Table 3: Fuzzy comparison matrix of sub-criteria with respect to quality of meal and its priority vectors

\begin{tabular}{|c|c|c|c|c|c|c|c|}
\hline Sub- & BSP & $\mathrm{ST}$ & $\mathrm{CP}$ & PS & & $\begin{array}{l}\text { Priority } \\
\text { Vector }\end{array}$ & \\
\hline \multirow[t]{2}{*}{ Criteria } & & & & & Extent & Modified & Potential \\
\hline & & & & & Analysis & F LLSM & Method \\
\hline BSP & $(1,1,1)$ & $(2 / 9,1 / 4,2 / 7)$ & $(7 / 2,4,9 / 2)$ & $(2 / 7,1 / 3,2 / 5)$ & 0 & $\begin{array}{l}(0.1408, \\
0.1493, \\
0.1597)\end{array}$ & 0.078 \\
\hline $\mathrm{ST}$ & $(7 / 2,4,9 / 2)$ & $(1,1,1)$ & $(7 / 2,4,9 / 2)$ & $(5 / 2,3,7 / 2)$ & 0.99 & $\begin{array}{l}(0.4826 \\
0.5173 \\
0.5472)\end{array}$ & 0.465 \\
\hline $\mathrm{CP}$ & $(2 / 9,1 / 4,2 / 7)$ & $(2 / 9,1 / 4,2 / 7)$ & $(1,1,1)$ & $(2 / 7,1 / 3,2 / 5)$ & 0 & $\begin{array}{l}(0.0707 \\
0.0747 \\
0.0802)\end{array}$ & 0.028 \\
\hline PS & $(5 / 2,3,7 / 2)$ & $(2 / 7,1 / 3,2 / 5)$ & $(5 / 2,3,7 / 2)$ & $(1,1,1)$ & 0.01 & $\begin{array}{l}(0.2321 \\
0.2587 \\
0.2866)\end{array}$ & 0.167 \\
\hline
\end{tabular}

Table 4: Fuzzy comparison matrix of sub-criteria with respect to quality of service and its priority vectors

than the weight obtained from Modified FLLSM (0.2831) and PM (0.277) for Mertol.

Modified FLLSM and PM produce the same rank in selection of the best catering firm. The Modified FLLSM and PM indicate that the highest is Afiyetle followed by Durusu and the lowest is Mertol. However, Extent Analysis found Mertol is the best firm, followed by Durusu, with Afiyetle as the worst.

Mertol is found to be the best catering firm by using Extent Analysis 


\begin{tabular}{cccccccc}
\hline $\begin{array}{c}\text { Catering } \\
\text { Firms }\end{array}$ & Durusu & Mertol & Afiyetle & \multicolumn{3}{c}{ Priority Vector } \\
& & & & Extent & Modified & Potential \\
& & & & Analysis & F LLSM & Method \\
\hline Durusu & $(1,1,1)$ & $(5 / 2,3,7 / 2)$ & $(3 / 2,2,5 / 2)$ & 0.66 & $(0.4668,0.5278,0.5760)$ & 0.020 \\
Mertol & $(2 / 7,1 / 3,2 / 5)$ & $(1,1,1)$ & $(2 / 7,1 / 3,2 / 5)$ & 0 & $(0.1343,0.1396,0.1476)$ & 0.017 \\
Afiyetle & $(2 / 5,1 / 2,2 / 3)$ & $(5 / 2,3,7 / 2)$ & $(1,1,1)$ & 0.34 & $(0.2897,0.3325,0.3857)$ & 0.019 \\
\hline
\end{tabular}

Table 5: Fuzzy comparison matrix of three catering firms with respect to hygiene of meal and its priority vectors

\begin{tabular}{ccccccc}
\hline $\begin{array}{c}\text { Catering } \\
\text { Firms }\end{array}$ & Durusu & Mertol & Afiyetle & \multicolumn{3}{c}{ Priority Vector } \\
& & & & Extent & Modified & Potential \\
& & & & Analysis & F LLSM & Method \\
\hline Durusu & $(1,1,1)$ & $(2 / 3,1,3 / 2)$ & $(2 / 9,1 / 4,2 / 7)$ & 0 & $(0.1592,0.1840,0.2127)$ & 0.014 \\
Mertol & $(2 / 3,1,3 / 2)$ & $(1,1,1)$ & $(2 / 5,1 / 2,2 / 3)$ & 0 & $(0.1867,0.2318,0.2906)$ & 0.014 \\
Afiyetle & $(7 / 2,4,9 / 2)$ & $(3 / 2,2,5 / 2)$ & $(1,1,1)$ & 1 & $(0.5502,0.5842,0.6006)$ & 0.016 \\
\hline
\end{tabular}

Table 6: Fuzzy comparison matrix of three catering firms with respect to hygiene of service personnel and its priority vectors

\begin{tabular}{ccccccc}
\hline $\begin{array}{c}\text { Catering } \\
\text { Firms }\end{array}$ & Durusu & Mertol & Afiyetle & \multicolumn{3}{c}{ Priority Vector } \\
& & & & Extent & Modified & Potential \\
& & & & Analysis & F LLSM & Method \\
\hline Durusu & $(1,1,1)$ & $(2 / 3,1,3 / 2)$ & $(2 / 7,1 / 3,2 / 5)$ & 0 & $(0.1781,0.2098,0.2477)$ & 0.015 \\
Mertol & $(2 / 3,1,3 / 2)$ & $(1,1,1)$ & $(2 / 5,1 / 2,2 / 3)$ & 0 & $(0.1933,0.2402,0.3015)$ & 0.015 \\
Afiyetle & $(5 / 2,3,7 / 2)$ & $(3 / 2,2,5 / 2)$ & $(1,1,1)$ & 1 & $(0.5203,0.5499,0.5590)$ & 0.017 \\
\hline
\end{tabular}

Table 7: Fuzzy comparison matrix of three catering firms with respect to hygiene of service vehicles and its priority vectors

whereby Mertol is identified as the worst firm selected by Modified FLLSM and PM. The weight of Mertol is higher by Extent Analysis as some important criteria were assigned as zero weight. Extent Analysis produced less preferable decision since some important criteria were neglected.

The Modified FLLSM and PM are appropriate methods to use in deriving priorities or weight of decision criteria, in contrast to Extent Analysis. However, Extent Analysis is a method that can show degree of priority for one criterion in a fuzzy comparison matrix. 


\begin{tabular}{ccccccc}
\hline $\begin{array}{c}\text { Catering } \\
\text { Firms }\end{array}$ & Durusu & Mertol & Afiyetle & \multicolumn{3}{c}{ Priority Vector } \\
& & & & Extent & Modified & Potential \\
& & & & Analysis & F LLSM & Method \\
\hline Durusu & $(1,1,1)$ & $(2 / 7,1 / 3,2 / 5)$ & $(2 / 3,1,3 / 2)$ & 0 & $(0.1805,0.2223,0.2670)$ & 0.010 \\
Mertol & $(5 / 2,3,7 / 2)$ & $(1,1,1)$ & $(1,1,1)$ & 0.97 & $(0.4566,0.4566,0.4566)$ & 0.010 \\
Afiyetle & $(2 / 3,1,3 / 2)$ & $(1,1,1)$ & $(1,1,1)$ & 0.03 & $(0.2764,0.3211,0.3629)$ & 0.010 \\
\hline
\end{tabular}

Table 8: Fuzzy comparison matrix of three catering firms with respect to variety of meal and its priority vectors

\begin{tabular}{cccccccc}
\hline $\begin{array}{c}\text { Catering } \\
\text { Firms }\end{array}$ & Durusu & Mertol & Afiyetle & \multicolumn{3}{c}{ Priority Vector } \\
& & & & Extent & Modified & Potential \\
& & & & Analysis & F LLSM & Method \\
\hline Durusu & $(1,1,1)$ & $(5 / 2,3,7 / 2)$ & $(2 / 3,1,3 / 2)$ & 0.87 & $(0.3967,0.4602,0.5144)$ & 0.010 \\
Mertol & $(2 / 7,1 / 3,2 / 5)$ & $(1,1,1)$ & $(1,1,1)$ & 0 & $(0.2207,0.2207,0.2207)$ & 0.009 \\
Afiyetle & $(2 / 3,1,3 / 2)$ & $(1,1,1)$ & $(1,1,1)$ & 0.13 & $(0.2648,0.3190,0.3825)$ & 0.009 \\
\hline
\end{tabular}

Table 9: Fuzzy comparison matrix of three catering firms with respect to complementary of meal and its priority vectors

\begin{tabular}{ccccccc}
\hline $\begin{array}{c}\text { Catering } \\
\text { Firms }\end{array}$ & Durusu & Mertol & Afiyetle & \multicolumn{3}{c}{ Priority Vector } \\
& & & & Extent & Modified & Potential \\
& & & & Analysis & F LLSM & Method \\
\hline Durusu & $(1,1,1)$ & $(2 / 9,1 / 4,2 / 7)$ & $(2 / 7,1 / 3,2 / 5)$ & 0 & $(0.1130,0.1207,0.1313)$ & 0.011 \\
Mertol & $(7 / 2,4,9 / 2)$ & $(1,1,1)$ & $(2 / 7,1 / 3,2 / 5)$ & 0.31 & $(0.2794,0.3043,0.3341)$ & 0.011 \\
Afiyetle & $(5 / 2,3,7 / 2)$ & $(5 / 2,3,7 / 2)$ & $(1,1,1)$ & 0.69 & $(0.5346,0.5750,0.6075)$ & 0.012 \\
\hline
\end{tabular}

Table 10: Fuzzy comparison matrix of three catering firms with respect to calorie of meal and its priority vectors

\section{Conclusions}

The aim of this study is to illustrate the application of PM to the problem posted in [7]. The comparison of weights from this study is compared to result obtained from Extent Analysis and Modified FLLSM. The PM and Modified FLLSM are found to be suitable approaches in determining criteria weights of AHP. The Extent Analysis is found less preferable in weight determination since it assigned a zero weight to some criteria. 


\begin{tabular}{ccccccc}
\hline $\begin{array}{c}\text { Catering } \\
\text { Firms }\end{array}$ & Durusu & Mertol & Afiyetle & \multicolumn{3}{c}{ Priority Vector } \\
& & & & Extent & Modified & Potential \\
& & & & Analysis & F LLSM & Method \\
\hline Durusu & $(1,1,1)$ & $(2 / 3,1,3 / 2)$ & $(1,1,1)$ & 0 & $(0.2731,0.3126,0.3849)$ & 0.008 \\
Mertol & $(2 / 3,1,3 / 2)$ & $(1,1,1)$ & $(2 / 9,1 / 4,2 / 7)$ & 0 & $(0.1604,0.1966,0.2361)$ & 0.008 \\
Afiyetle & $(1,1,1)$ & $(7 / 2,4,9 / 2)$ & $(1,1,1)$ & 1 & $(0.4908,0.4908,0.4908)$ & 0.008 \\
\hline
\end{tabular}

Table 11: Fuzzy comparison matrix of three catering firms with respect to taste of meal and its priority vectors

\begin{tabular}{ccccccc}
\hline $\begin{array}{c}\text { Catering } \\
\text { Firms }\end{array}$ & Durusu & Mertol & Afiyetle & \multicolumn{3}{c}{ Priority Vector } \\
& & & & Extent & Modified & Potential \\
& & & & Analysis & F LLSM & Method \\
\hline Durusu & $(1,1,1)$ & $(7 / 2,4,9 / 2)$ & $(5 / 2,3,7 / 2)$ & 1 & $(0.6110,0.6337,0.6489)$ & 0.029 \\
Mertol & $(2 / 9,1 / 4,2 / 7)$ & $(1,1,1)$ & $(1,1,1)$ & 0 & $(0.1705,0.1744,0.1804)$ & 0.024 \\
Afiyetle & $(2 / 7,1 / 3,2 / 5)$ & $(1,1,1)$ & $(1,1,1)$ & 0 & $(0.1797,0.1919,0.2086)$ & 0.025 \\
\hline
\end{tabular}

Table 12: Fuzzy comparison matrix of three catering firms with respect to behavior of service personnel and its priority vectors

\begin{tabular}{ccccccc}
\hline $\begin{array}{c}\text { Catering } \\
\text { Firms }\end{array}$ & Durusu & Mertol & Afiyetle & \multicolumn{3}{c}{ Priority Vector } \\
& & & & Extent & Modified & Potential \\
& & & & Analysis & F LLSM & Method \\
\hline Durusu & $(1,1,1)$ & $(3 / 2,2,5 / 2)$ & $(2 / 7,1 / 3,2 / 5)$ & 0.05 & $(0.2443,0.2827,0.3291)$ & 0.138 \\
Mertol & $(2 / 5,1 / 2,2 / 3)$ & $(1,1,1)$ & $(7 / 2,4,9 / 2)$ & 0.64 & $(0.3729,0.4142,0.4614)$ & 0.190 \\
Afiyetle & $(5 / 2,3,7 / 2)$ & $(2 / 9,1 / 4,2 / 7)$ & $(1,1,1)$ & 0.31 & $(0.2904,0.2987,0.3018)$ & 0.138 \\
\hline
\end{tabular}

Table 13: Fuzzy comparison matrix of three catering firms with respect to service time and its priority vectors

The Modified FLLSM and PM are found to be suitable approaches in determining the weight due to their ability to produce better weight than Extent Analysis. The PM is found to be comparable to Modified FLLSM. However, $\mathrm{PM}$ is found to be simpler to implement than Modified FLLSM. 


\begin{tabular}{ccccccc}
\hline $\begin{array}{c}\text { Catering } \\
\text { Firms }\end{array}$ & Durusu & Mertol & Afiyetle & \multicolumn{3}{c}{ Priority Vector } \\
& & & & Extent & Modified & Potential \\
& & & & Analysis & F LLSM & Method \\
\hline Durusu & $(1,1,1)$ & $(7 / 2,4,9 / 2)$ & $(2 / 3,1,3 / 2)$ & 0.86 & $(0.4242,0.4934,0.5573)$ & 0.010 \\
Mertol & $(2 / 9,1 / 4,2 / 7)$ & $(1,1,1)$ & $(2 / 3,1,3 / 2)$ & 0 & $(0.1782,0.1958,0.2098)$ & 0.009 \\
Afiyetle & $(2 / 3,1,3 / 2)$ & $(2 / 3,1,3 / 2)$ & $(1,1,1)$ & 0.14 & $(0.2329,0.3108,0.3976)$ & 0.009 \\
\hline
\end{tabular}

Table 14: Fuzzy comparison matrix of three catering firms with respect to communication on phone and its priority vectors

\begin{tabular}{ccccccc}
\hline $\begin{array}{c}\text { Catering } \\
\text { Firms }\end{array}$ & Durusu & Mertol & Afiyetle & \multicolumn{3}{c}{ Priority Vector } \\
& & & & Extent & Modified & Potential \\
& & & & Analysis & F LLSM & Method \\
\hline Durusu & $(1,1,1)$ & $(1,1,1)$ & $(2 / 9,1 / 4,2 / 7)$ & 0 & $(0.1714,0.1769,0.1769)$ & 0.047 \\
Mertol & $(1,1,1)$ & $(1,1,1)$ & $(2 / 7,1 / 3,2 / 5)$ & 0 & $(0.1782,0.1922,0.2101)$ & 0.049 \\
Afiyetle & $(7 / 2,4,9 / 2)$ & $(5 / 2,3,7 / 2)$ & $(1,1,1)$ & 1 & $(0.6130,0.6309,0.6505)$ & 0.072 \\
\hline
\end{tabular}

Table 15: Fuzzy comparison matrix of three catering firms with respect to problem solving ability and its priority vectors

\begin{tabular}{cccc}
\hline Catering & \multicolumn{3}{c}{ Priority Vector } \\
& Extent Analysis & Modified F LLSM & Potential Method \\
\hline Durusu & 0.462 & $(0.3055,0.3642,0.4089)$ & 0.049 \\
Mertol & 0 & $(0.1612,0.1878,0.2280)$ & 0.042 \\
Afiyetle & 0.538 & $(0.4082,0.4498,0.4919)$ & 0.055 \\
\hline
\end{tabular}

Table 16: Local weights of three catering firms with respect to hygiene

\begin{tabular}{cccc}
\hline Catering & \multicolumn{3}{c}{ Priority Vector } \\
& Extent Analysis & Modified F LLSM & Potential Method \\
\hline Durusu & 0.044 & $(0.1910,0.2265,0.2673)$ & 0.037 \\
Mertol & 0.420 & $(0.2950,0.3172,0.3406)$ & 0.038 \\
Afiyetle & 0.537 & $(0.4043,0.4563,0.5027)$ & 0.041 \\
\hline
\end{tabular}

Table 17: Local weights of three catering firms with respect to quality of meal

\section{Acknowledgements}

This research is supported by a FRGS vote 4F756 of MOHE, Malaysia. The authors are thankful for the financial support. 


\begin{tabular}{cccc}
\hline Catering & \multicolumn{3}{c}{ Priority Vector } \\
& Extent Analysis & Modified F LLSM & Potential Method \\
\hline Durusu & 0.050 & $(0.2878,0.3258,0.3631)$ & 0.221 \\
Mertol & 0.634 & $(0.2709,0.3047,0.3434)$ & 0.244 \\
Afiyetle & 0.317 & $(0.3430,0.3696,0.3963)$ & 0.273 \\
\hline
\end{tabular}

Table 18: Local weights of three catering firms with respect to quality of service

\begin{tabular}{cccc}
\hline Catering & \multicolumn{3}{c}{ Priority Vector } \\
& Extent Analysis & Modified F LLSM & Potential Method \\
\hline Durusu & 0.050 & $(0.2618,0.3096,0.3559)$ & 0.286 \\
Mertol & 0.634 & $(0.2484,0.2831,0.3221)$ & 0.277 \\
Afiyetle & 0.317 & $(0.3707,0.4072,0.5554)$ & 0.437 \\
\hline
\end{tabular}

Table 19: Global weights of three catering firms with respect to goal

\section{References}

[1] T.L. Saaty, How to make a decision: The Analytic Hierarchy Process, European Journal of Operational Research, 48 (1990), 9-26, doi: 10.1016/0377-2217(90)90057-I.

[2] C.C. Huang, P.Y. Chu and Y.H. Chiang, A fuzzy AHP application in governmentsponsored R\&D project selection, Omega, 36 (2008), 1038-1052.

[3] M.C.Y. Tam and V.M.R. Tummala, An application of the AHP in vendor selection of a telecommunication system, Omega, 29 (2001), 171-182, doi: 10.1016/S03050483(00)00039-6.

[4] E.W.T. Ngai, Selection of web sites for online advertising using the AHP, Information and Management, 40 (2003), 233-242, doi: 10. 1016/S0378-7206(02)00004-6.

[5] M. T. Nouei, A. V. Kamyad, S. Ghazalbash and M. Sarzaeem, Application of fuzzy-AHP extent analysis to determine the relative importance of risk factor in operative mortality after Coronary Artery Bypass surgery, International Journal on Computer Science and Engineering, 5(5) (2013), 393-401.

[6] R. Radhakrishnan and A. Kalaichelvi, Selection of the best school for the children A decision making model using extent analysis method on Fuzzy Analytic Hierarchy Process, International Journal of Innovative Research in Science, Engineering and Technology, 3(5) (2014), 12334-12344.

[7] Y.M. Wang, Y. Luo and Z. Hua, On the extent analysis method for fuzzy AHP and its applications, European Journal of Operational Research, 186 (2008), 735-747, doi: 10.1016/j.ejor.2007.01.050.

[8] R. Aggarwal and S. Singh, AHP and Extent Fuzzy AHP Approach for Prioritization of Performance Measurement Attributes, International Journal of Mechanical, Aerospace, Industrial, Mechatronic and Manufacturing Engineering, 7(1) (2013), 6-11. 
[9] Y-M. Wang, T.M.S. Elhag and Z. Hua, A Modified fuzzy logarithmic least square method for fuzzy analytic hierarchy process, Fuzzy Sets and Systems, 157 (2006), 3055-3071, doi: 10.1016/j.fss.2006.08.010.

[10] L.Čaklović, Decision Making by Potential Method, preprint (2002).

[11] L. Čaklović and V. Sego, Potential Method Applied on Exact Data, Proceedings of 9th International Conference on Operational Research KOI2002, Croatian Operational Research Society, (2002), 237-248.

[12] L. Čaklović and S. Radas, Application of Potential Method to survey analysis, Mathematical Communications, 19 (2014), 397-415.

[13] L. Čaklović, An IO- Modification of Potential Method, Electronic Notes in Discrete Mathematics, 33 (2009), 131-138, doi: 10.1016/j.endm.2009.03.019

[14] R. Goetscheal and W. Voxman, Topological Properties of Fuzzy Numbers, Fuzzy Sets and System, 10 (1983), 87-99, doi: 10.1016/S0165-0114(83)80107-9.

[15] D.Y. Chang, Applications of the extent analysis method on fuzzy AHP, European Journal of Operational Research, 96 (1996), 649-655, doi: 10.1016/0377-2217(95)00300-2.

[16] K.K.F. Yuen and H.C.W Lau, Software Vendor Selection using Fuzzy Analytic Hierarchy Process with ISO/IEC 9126, IAENG International Journal of Computer Sciences, (2008). 
